\title{
MOVEMENT AS A DESIGN PARAMETER: STUDIO WORKS 2014-2016
}

\author{
D.G. OZER \& A.A. KAVAKOGLU \\ Department of Architecture, Istanbul Kemerburgaz University, Turkey.
}

\begin{abstract}
In the relationship of design and nature, movement is one of the major concepts that can be considered in every design scale. Therefore, this study tries to reveal the various integration of movement notion/ concept into design problems in architectural design education, aiming to use movement data as a design parameter. Space, time and movement are a very complex triple to articulate in a design problem but at the same time, the analysis of movement notion and search for its impacts in design, stretch the students' way of design thinking.

Regarding the above statement, three courses are conducted as a series of design studios, within Istanbul Kemerburgaz University (IKBU) Department of Architecture. The case studies focused in this paper based on design projects take place during ARCH 101-Basic Design, ARCH 284-Introduction to Digital Design and ARCH 301-Architectural Design courses between 2014 and 2016. These courses aim to develop a common ground for a computational way of thinking in the curricula. Regarding this aim; all three courses are designed within a similar methodology that targets the integration of (1) capturing/recording (2) analyzing, and (3) embodying/materializing/articulation of movement into design process.

Finally, this paper is an experimental study on using movement data in design process of architectural design education. The results of the studios are compared within their processes, and it has been observed that when design experience increases, students tend to spend more time in materializing the design rather than capturing and analyzing the movements.
\end{abstract}

Keywords: architectural design, computational thinking, design education, design thinking, movement.

\section{INTRODUCTION}

In nature, movement is a key concept that every living being has a movement path in their daily life. In design, this can either be bodily or the daily movement path of people in everyday life in urban scale or flow of sand particles in an hourglass in a smaller scale. In both scales, it is important to observe and understand what movement is, to use it as a design parameter.

Movement is often defined as the act, process or result of moving [1] in other words, the act or process of moving people or things from one place or position to another [2]. Despite its simplified literal definition, defining the movement regarding its characteristics is not an easy task because of its link with space and time notions.

Many researchers, artists, scientist, etc. has questioned the essence of movement relevant with time and space notions through its visuality for centuries. Starting from the motion studies of Etienne-Jules Marey, and Eadweard Muybridge at the 19th century, which affected the ways of seeing and perception by the birth of chronophotography - capturing the nature of movement, has been at the core as an issue for art, science and architecture fields. 
The articulation of the above-mentioned issue in art, especially in visual arts, has been questioned by futurists [3-5]. They researched the ways of representing movement in their paintings. As well as capturing the movement, its analyzation, and its visual representation started to be an interest in the early 20th century not merely for visual arts but also for performance-based arts as dancing.

While some of the researchers concentrated on the notation of human movement, some of them examined the bodily movement as a transformative object. Among many studies Oscar Schlemmer's and Rudolf Laban's works on movement comes into prominence because of their validity and effects on today's researches. For example Schlemmer's stereometric approach focusing on the exploration of the spatial relationship between human body and geometry has an impact on today's motion capture technology [6, 7].

Laban focused on the conceptualization of spatial forms through the bodily movements and positions. He created a notation system, called Labanotation to record and analyze human movements in 1928. The term 'choreutics' he discussed was considering laws of structuring movement [8]. These debates were also oriented architecture to a common ground in which the movement studies' scope started to transform from a visual inquiry into a more haptic and experiential entity. Many architects have argued that the isolation of space from movement and time notions, disregards the nature of spatial context $[4,9]$. While some of them were working on its effects on form generation by using developed digital technologies, some of them approached it as an analysis method through the articulation of human movement within the (build) environment.

According to Aristotle, movement analysis is a method to break down the complexity of movement, and recompose an object of knowledge in a systematic way [10]. We have to reconsider movement, apart from being only a visual concept, or we lose the data in it. Kinetic formalism, in other words, 'kinetopoiesis', can be a better understanding of an external and rule-based representation of constructing bodily movement. The above-mentioned construction is a creative act involving both computation and artistry [10]. Moreover, the reciprocal relationship between these two notions linked to the corporeal qualities of movement, reveals the significance of movement as data [11].

Regarding this literature, it can be said that there are many researches exploring the potential ways of using movement data in the design process. However, there are few studies to work on movement data in architectural design education throughout the curricula. Therefore, this paper aims to experiment a model on how to use movement data and how such data can be used in the design process in architectural design education.

\section{MOVEMENT AS A DESIGN PARAMETER: CASE STUDIES}

This study is conducted within three courses in Department of Architecture, Istanbul Kemerburgaz University/Turkey. These courses are ARCH 101-Basic Design (first-year undergraduate), ARCH 284-Introduction to Digital Design (second-year undergraduate) and ARCH 301-Architectural Design (third-year undergraduate). The scale and the theme of the design problems were different, as well as the duration of the design process. Since the students are asked to design with movement data, their process is observed in three phases: (1) capturing/ recording (2) analyzing, and (3) embodying/materializing/ articulation. This study aims to compare the design processes of each year's students, to understand the duration of the phases of their design process, and how they integrate this method into their design projects. 
2.1 Move[M]Body: computing the body movement

Move[M]Body project is a part of ARCH-101 Basic Design course during six weeks for the first year undergraduate architecture students. The aim of the project is to investigate how to compute the body movement and then materialize it.

The assignment has three phases, Fig. 1. Initially, the students are asked to shot a video of their body movement (walking, dancing, jumping, etc.) for 30 seconds. Secondly, they start to analyze the bodily movement through the video regarding the four main formal characteristics of the movement that are velocity, position, repetition and duration [11]. They map these characteristics on a $2 \mathrm{D}$ and $3 \mathrm{D}$ diagram to examine the essence of the movement. And as the last step, they structure and materialize the analyzed movement regarding the characteristics by using linear, planar or solid forms. In other words, they re-embody their body movements through design elements. The main focus is on the spatial construction that is produced through these embodiments. The spatial experiential aspect of the bodily movement has been excluded during this embodiment process because of its complex essence. Instead of concentrating on the bodily experience through movement, the design problem focuses on the (spatial) embodiment of the body movement.

Students articulate their body movement step-by-step regarding its various aspects. They concentrate on materialization through movement's multi-dimensional characteristics. In other words, they tried to figure out movement's algorithm as its essence. To reach that goal, the movement, as the given design problem should be defined step-by-step regarding its parameters, variables, constraints that are position, velocity, duration and repetition $[11,12]$.

The three phases; capturing, analyzing and materializing cannot be separated sharply from each other. These phases include abstraction, formalization and representation acts in which the exploration of movement data varies. Students abstract, formalize and represent their movement through a rule-based system that they generate during analyzing and materializing phases, Fig. 2. They concentrate on the transformation of 2D and 3D elements regarding shape and form, exploring their relationship with the fourth dimension, which is the time parameter. These analyses feed the foundation of the invisible nature of the movement linked

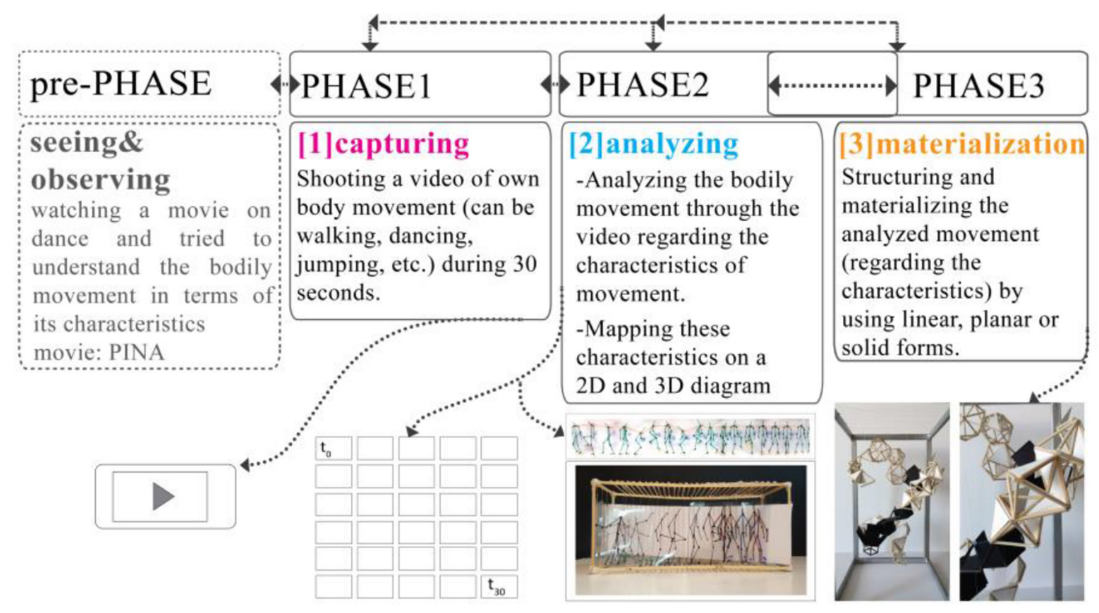

Figure 1: Process of Move[M]Body Project. 
to space and time. Afterwards, in materialization phase, they map the nature of the movement onto materials through its parameters.

While some of the students approach movement through its geometry, some of them try to formalize it. Although many of the students start the 2D analysis through chronophotographic diagrams, some of them construct their notation system through the formalization of their movement, Fig. 3. In other words they produce their vocabulary and in some cases a language

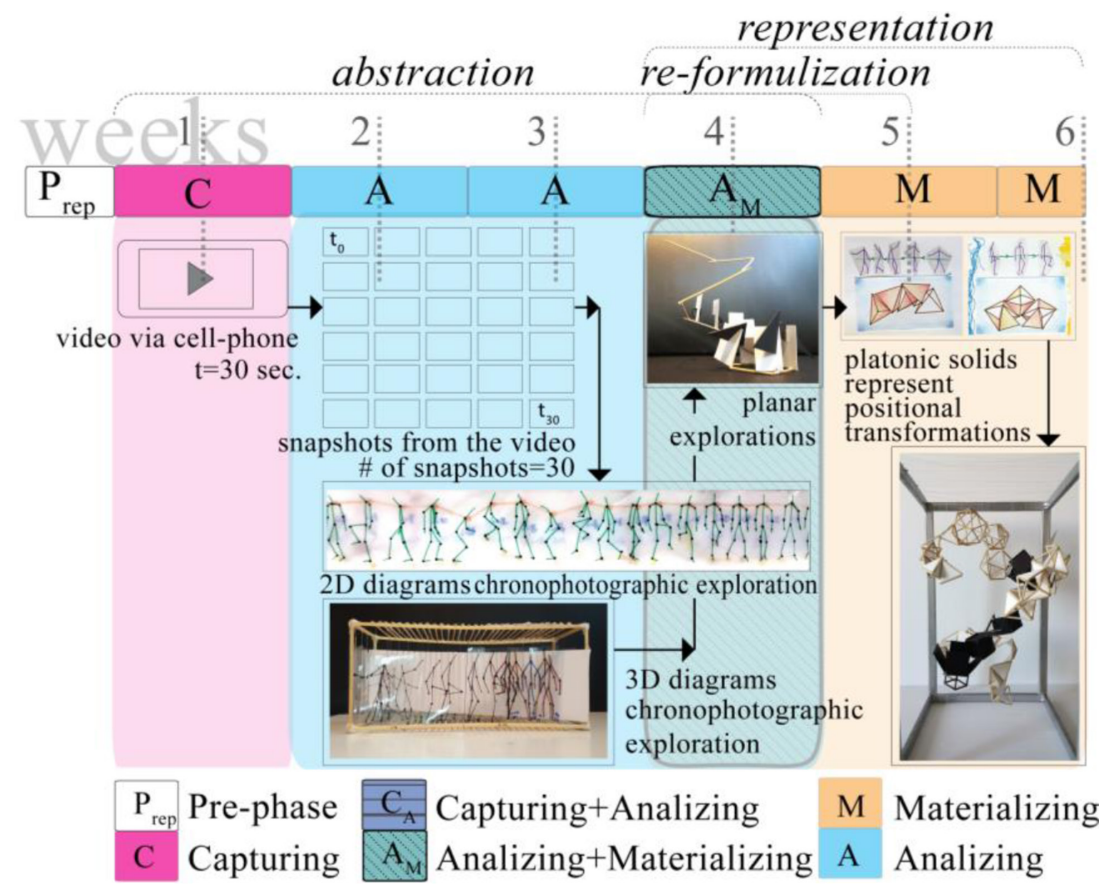

Figure 2: Weekly duration of the phases of capturing, analyzing and materializing (student work: M. Leke).

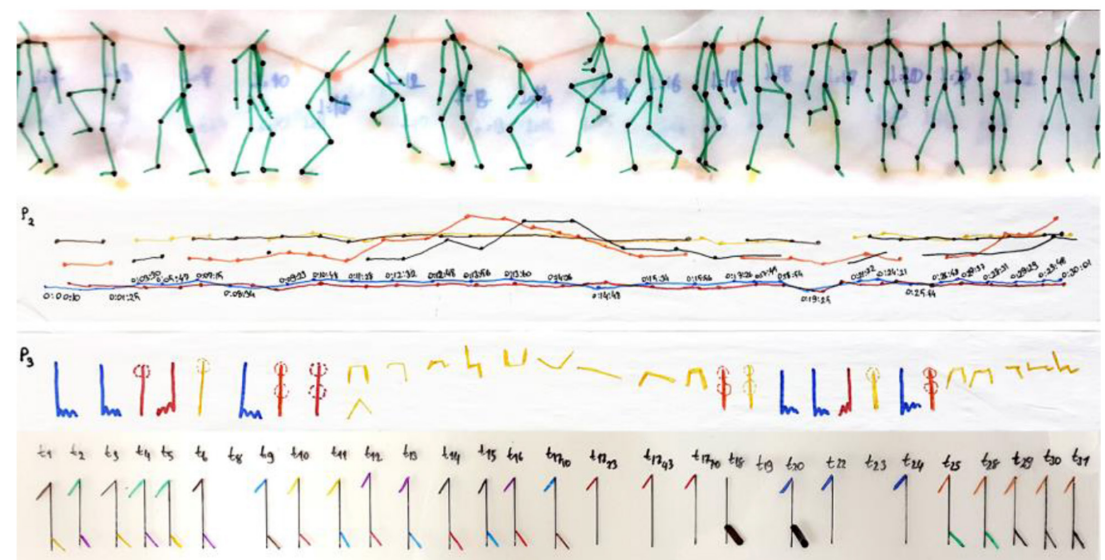

Figure 3: Examples of 2D diagrams during the analyzation phase: From chronophotographic analysis to notation of movement (student works: M. Leke, M. Yilmaz \& Z. Sarmusak). 

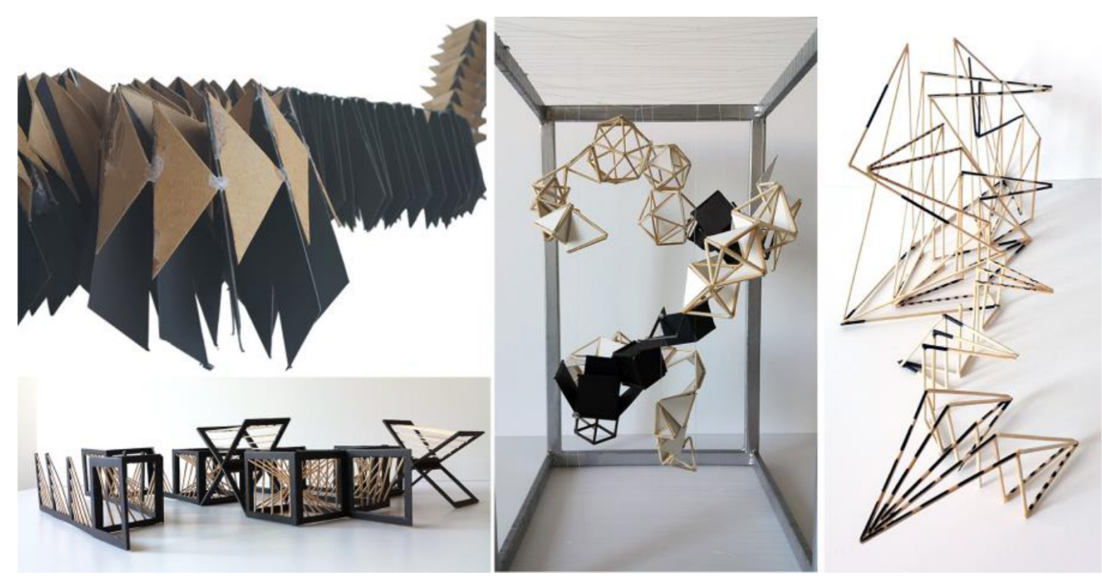

Figure 4: Final models after materialization phase (student works: S. Firat, M. Yilmaz, M. Leke \& Z. Sarmusak).

defining their bodily movement as in Laban's notation system. During the construction of this rule based definition, students start to understand the nature of movement and its relationship with spatial construction within its methodology.

As a result, capturing the $2 \mathrm{D}$ and $3 \mathrm{D}$ data and transforming them into other mediums, shapes or forms, through a step-by-step procedure, start to stretch students' way of design thinking. They begin to understand how the data orients their materialization phase. In other words, they figure out the various ways to compute their bodily movement and explore the reciprocal relationship between the design phases.

As a result, this assignment provides a foundation for constructing a way of computational thinking. It raises awareness on possible configurations through the captured data and constitutes the use of analysis during a design process. It also gives the ability to gather all these phases for the final product, which is the materialized body movement in this case, Fig. 4.

\subsection{Move[CAM]: parametric designs for the spaces around us}

Move[CAM] project has been a part of ARCH-284 Introduction to Digital Design course during 2014-2015 spring semester. Students have learned Rhinoceros and Grasshopper softwares for the first seven weeks, called as pre-phase in this study. They develop their own projects in groups aiming to capture and analyze the movement using both digital and algorithmic modeling tools. After capturing and analyzing phases, students materialize their design decisions based on the nature of movement parameters, Fig. 5.

Some groups capture the body movements, while some others are analyzing different modes of movement following two weeks. Afterwards, students chose various fabrication methods, and they execute it using different materials during the materialization phase in one to one scale. When materializing the movement, there were five project groups. Among these groups, the scale was various, from the spatial arrangements of daily circulation to the movement of sand particles. Two of them are explained as followed:

One of the projects, TriPASS, focuses on the spatial arrangements of daily circulation in a university building, Fig. 6 . The project resembles Schlemmer's argument on moving body, which plays an important role in the evolution of basic geometry of spatial stereometry [6]. 


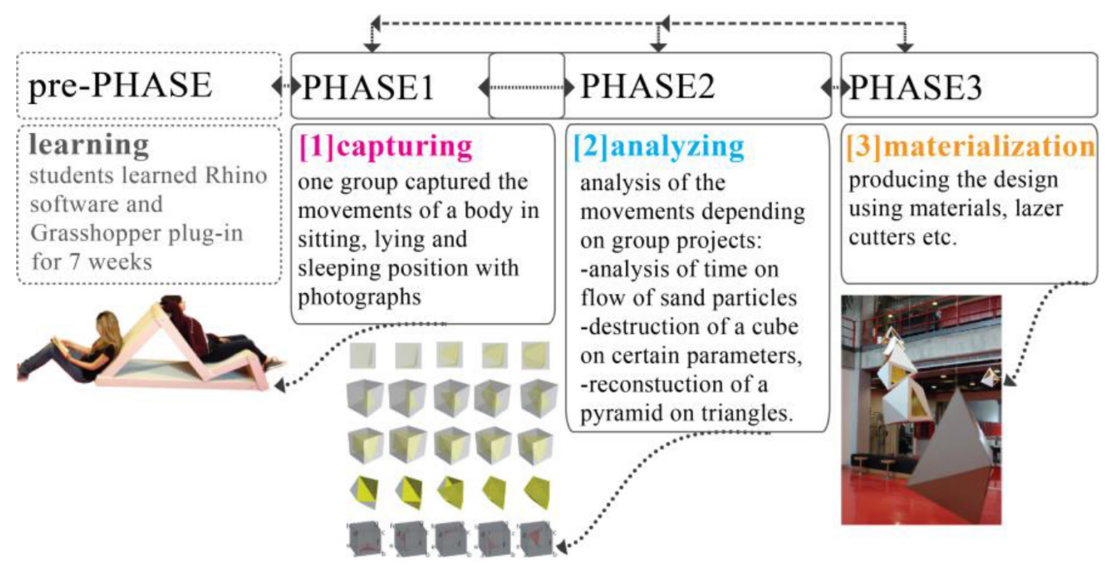

Figure 5: Process of Move[CAM] Project.

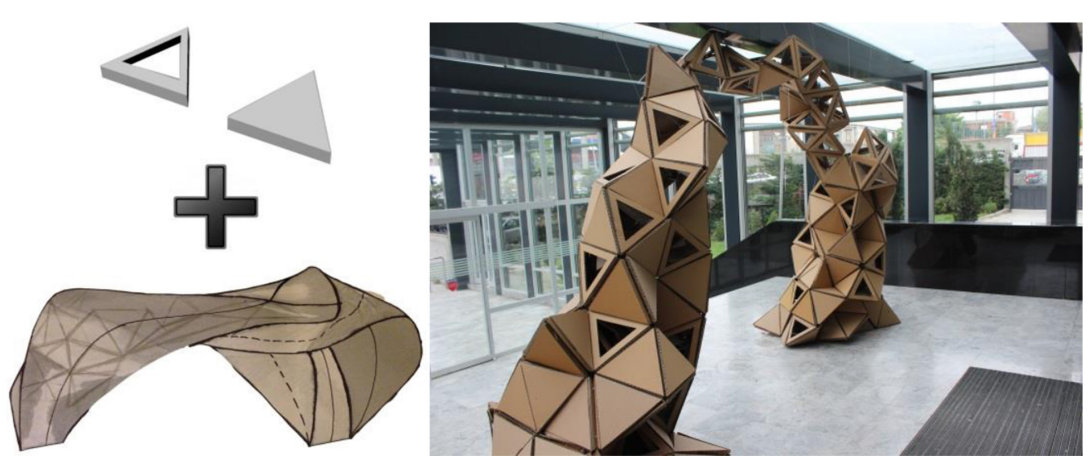

Figure 6: TriPASS project (group work: D. Yasar, M. Ciltas, I. Yilmaz, C. Eribol, E.M. Aktas \& E. Atalay).

Stereometry is an area to work with volumetric measurements and various solid figures. In order to understand the volumetric relationship, Schlemmer suggests assuming the void as solid, and solid (body) as void. Then the movement of a body, like carving in a solid, reflects the spatial stereometry between the body and the environment. Depending on this argument, the project aims to identify its surrounding space and act as a passageway at the gate of the campus. The students have analyzed the body movements (standing and sitting positions) of humans, and also the walking routes for cats. It is also important to use natural light as a design parameter to create a spacious area underneath.

The group associate these parameters with uniform triangle shapes $(30 \times 30 \times 30 \mathrm{~cm})$. They use the solid void relationship linked to the spatial effect of light. Afterwards, they transform the 2D shaped design into 3D forms by connecting the sides or surfaces with different angles.

The other project is called Juriescope, which aims to make an experimental design of an hourglass depending on the movement of sand particles' flow and time as parameters, Fig. 7. In the materializing phase, students cut a hundred pieces of plexiglass squares, which have three holes in them. These holes form the tubes for sand particles to flow. They place these pieces on top of each other with a $4^{\circ}$ rotation. There are three boxes of sand on top and bottom of the hourglass, which also have different colors. The students have designed the hourglass so 

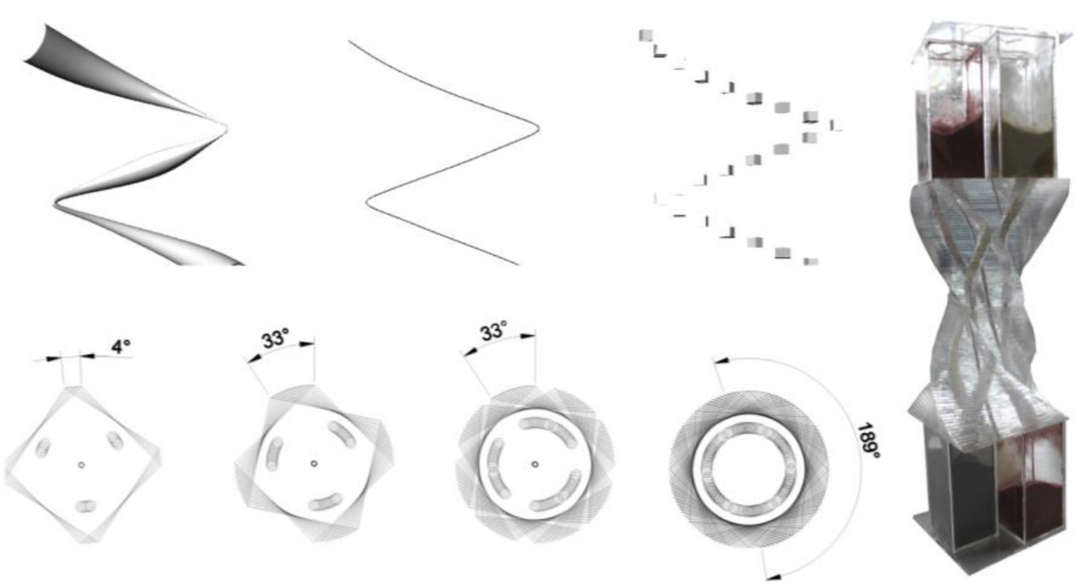

Figure 7: Juriescope project showing the sectional diagrams of the design (M. Polat, N. Sengul, F. Danalioglu, M.N. Hashi \& A.C. Akdeniz).

that the red sand particles will flow down in ten minutes, green particles in seven, and blue particles in five. The design is aimed to be used in a jury, so the students will know how much time he/she is left. The color of the sand particles is linked to the time parameter.

\subsection{Move[URB]: interpretations on gelibolu harbour}

Move[URB] project has been implemented in ARCH-301 Architectural Design III course during 2014-2015 fall semester. The aim of this course is to encourage the use of design ability built up during the first and second years of programmatic development and design of an urban district through focusing on movements of human/vehicle etc. Gelibolu/Turkey is chosen as the project site since various kinds of movements happen in this historical context. The students are expected to:

- Understand the forces that (re) form the city and its infrastructures.

- Identify the relationship between movement and the city regarding user and the designer.

- Interpret movement as a design parameter in architectural design.

- $(\mathrm{Re})$ form the relations and structures through movement at urban context.

During the first week, the students read the movement literature and analyze the architectural program before going to the site. In the second week, there is a field trip to Gelibolu/ Turkey, where students analyze the context, make diagrams based on their observation of human and vehicle movement, and also interview with people on their daily routines. After the fifth week to the end of the semester, students tried to articulate the movement schemes on the architectural program of a harbor museum. This articulation phase points out the transitional interrelations between human/vehicle movement in urban scale and architectural museum program in building scale, Fig. 8.

In the articulation of building scale, it has been observed that students had a hard time using the movement data while designing architectural spaces. The projects that were able to relate (and preferably transform) the urban movement analysis to museum user movement analysis were considered successful in the articulation of museum spaces, Fig. 9. 


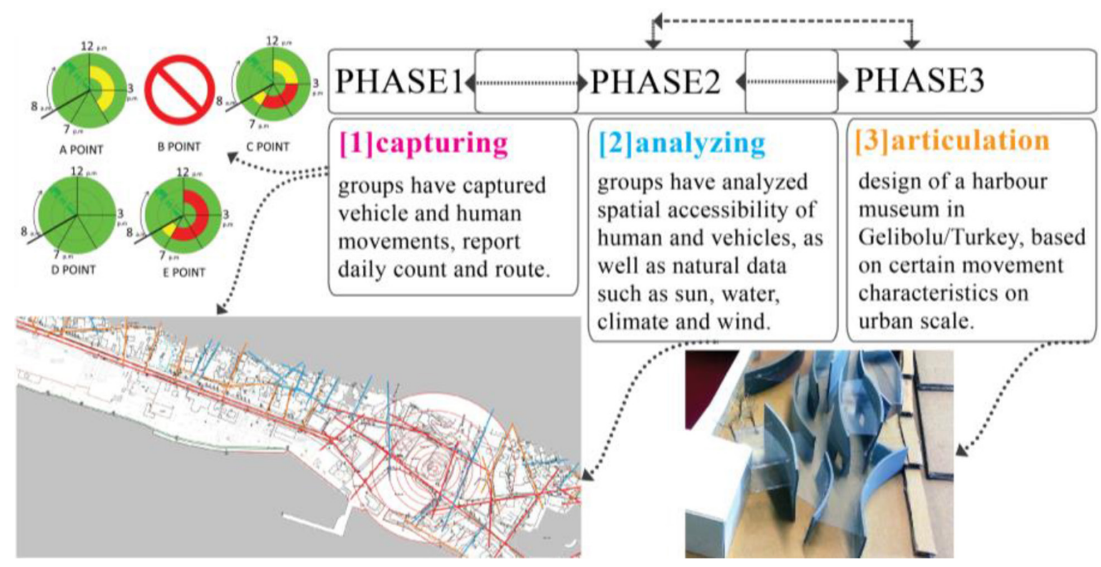

Figure 8: Phases of Move[URB] Project.
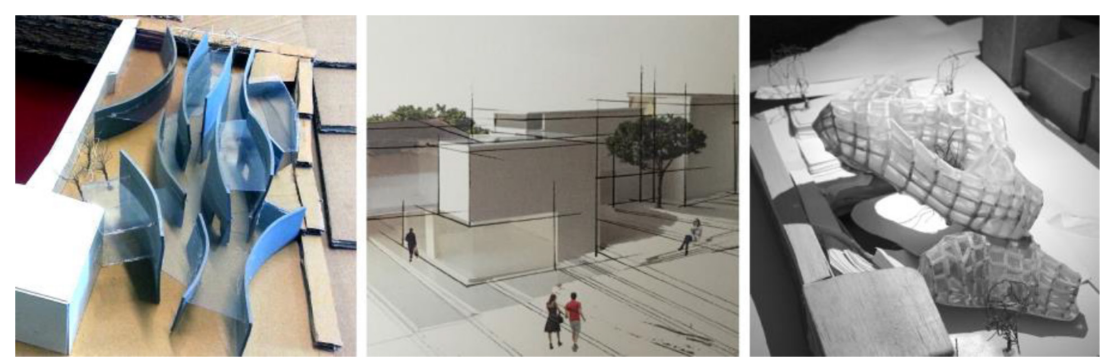

Figure 9: Articulation phase of Move[URB] (student works: H. Akca, S. Okdemir \& K. Utku).

\section{RESULTS AND CONCLUSION}

As a result of this examination through the different design problems integrated into first, second and third-year design courses, it has been observed that when the students' design experience and the ability to solve design problems increases; the three phases, capturing, analyzing and materializing, intertwine more and more, Fig. 10.

Another observation through these experimental studios is about the students' design thinking ability. Throughout these study, it can be said that the integration of movement as a design parameter to design problem opens a way for students to understand the invisible nature of the design problem inputs. The first year and second year students followed a stepby-step procedure, while the third year students' design steps intertwined more as aforementioned.

We have observed that when students get experienced in design problem solving, the phases of capturing and analyzing are ending in a shorter time span. Hence, students spend more time in the phases of embodying/ materializing and articulation.

Consequently, it can be said that the integration of movement as a design parameter in early (architecture) design education, accomplishes a better result in materializing an abstract phenomenon in the design process. The main reason for that is about the designers' experience and the complexity of the design problem; including concepts such as function and urban context. 


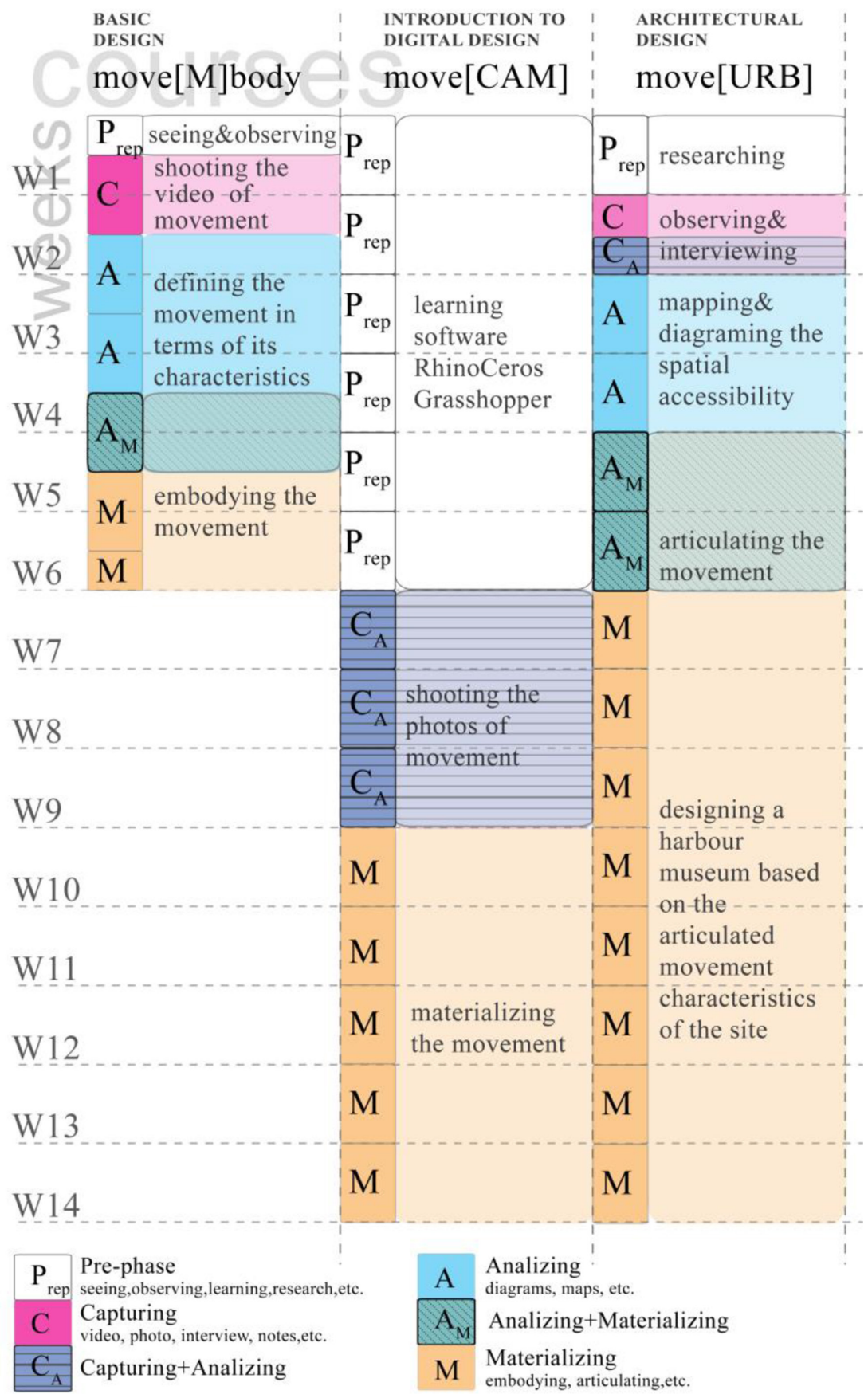

Figure 10: The comparision of the phases of three courses in different years of the architectural curricula. 
Finally the study has been achieved the following results:

- Interpret movement as a design parameter in architectural design.

- $(\mathrm{Re})$ form the relations and structures through movement at various scales.

- $(\mathrm{Re})$ integrate the movement concept into the design studios of the architectural design education curricula.

\section{ACKNOWLEDGEMENT}

All three courses were implemented and funded by İstanbul Kemerburgaz University Department of Architecture between 2014 and 2016. Firstly, we would like to thank our students who contributed in these courses and studied throughout the semester with a valuable effort. Secondly, we would like to thank the Municipality of Gelibolu for sharing the future project visions and accurate site drawings with us. We are grateful for Tomasz Malec's moral support during the site trip of Move[URB] project. We also would like to express our gratitudes to Handan As for sharing her valuable historical memory during the analyzation phase of the project.

The Move[M]Body project is a part of the Basic design course that has been re-designed during 2015-2016 academic year. We would like to give our sincere gratitudes to the coexecutors of the course; Isil Ekin Calak and Nilay Ozlu, and to the teaching assistants; M. Aygun Asik, Gulce Kirdar and Meltem Cetinel.

\section{REFERENCES}

[1] Online dictionary, available at: www.dictionary.com.

[2] Online dictionary, available at: www.merriam-webster.com.

[3] Giedion, S., Space, Time and Architecture, Massachusetts Harvard University Press: Cambridge, 1967.

[4] Lynn, G., Animate Form, Princeton Architectural Press: New York, 1999.

[5] Harris, H., From Moving Image to Moving Architecture, Cambridge and England, 2000.

[6] Nikolic, S., The bauhaus theater- oskar schlemmer's design-in motion concept. SAJ, 6 , pp. 43-62, 2014.

[7] Delbridge, M., Motion Capture in Performance: An Introduction,Palgrave Macmillan: Basingtoke, 2015.

[8] Maletic, V., Body-Space-Expression: The Development of Rudolf Laban's Movement and Dance Concepts, Mouton de Gruyter, 1987. http://dx.doi.org/10.1515/9783110861839

[9] Tshumi, B., Anodyne. In Architectural Design: Architecture+Animation, pp. 16-19, 2001.

[10] Sutil, N.S., Motion and Representation: The Language of Human Movement, MIT Press: Cambridge, 2015.

[11] Hansen, L.A. \& Morrison, A., Materializing movement- designing for movement-based digital interaction. International Journal of Design, 8(1), pp.29-42, 2014.

[12] Sorguc, G.A. \& Selcuk, A.S., Computational models in architecture: understanding multi-dimensionality and mapping. Nexus Network Journal, 15(2), pp. 349-362, 2013. http://dx.doi.org/10.1007/s00004-013-0150-z 